\title{
UMA REFLEXÃO ACERCA DO PAPEL DO ARQUITETO NA CONSTRUÇÃO DA PAISAGEM INFORMACIONAL ${ }^{1}$
}

\author{
A REFLECTION CONCERNING THE ROLE OF THE ARCHITECT \\ IN THE CONSTRUCTION OF INFORMATIONAL LANDSCAPES
}

\author{
Vanessa Casarin* \\ Alina Gonçalves Santiago**
}

\begin{abstract}
RESUMO
Este artigo tem como objetivo refletir sobre o papel do arquiteto na produção da paisagem informacional contemporânea, aquela dominada por signos e símbolos da comunicação visual urbana, na qual, muitas vezes, ocorre a situação de sobrecarga visual. Possui como objetivo, também, saber em que grau a relação entre paisagem e comunicação visual urbana tem sido abordada nas grades curriculares dos cursos de arquitetura e urbanismo das universidades brasileiras de maior visibilidade. A grade curricular destes cursos, na maioria das universidades pesquisadas, reflete a preocupação com o assunto no sentido de preparar o arquiteto para atuação nesta área, sendo o melhor exemplo entre as universidades pesquisadas a Universidade de São Paulo (USP). Parece haver pouca interferência do arquiteto na produção das paisagens com sobrecarga visual, uma vez que sua preocupação está em requalificá-las. Seu papel, além da conscientização da sociedade acerca desta problemática, está na participação mais efetiva em processos de controle destas manifestações na paisagem urbana, uma vez que o planejamento delas é sua atribuição profissional.
\end{abstract}

Palavras-chave: Arquitetura. Arquiteto. Comunicação visual. Paisagem.

\begin{abstract}
The aim of this article is to reflect about the role of the architect in the production of informational landscapes, the ones dominated by sign and symbols of urban visual communication, in which sometime-me occur a visual overload condition of stimulus and information; the paper is concern as well with the degree in which relationship between landscape and urban visual communication has been developed in the curriculum of Brazilian universities of major visibility. The curriculum of major universities analyzed reflects worry with this issue in a sense to prepare the architect to professional activities in this area, which best example is the University of São Paulo. It seems to have very little interference of the architect in the production of landscapes with visual overload since their major worry is to qualify this kind of landscape. Their role is, instead, in the conscientization of society concerning this issue, their role is also in the effective participation on controlling process and planning which is their professional attribute.
\end{abstract}

Keywords: Architecture. Architect. Visual communication. Landscape.

* Graduou-se em Arquitetura e Urbanismo e em Comunicação Social pela Universidade Federal de Santa Maria (UFSM). Doutora em Arquitetura e Urbanismo pela Universidade Federal de Santa Catarina (UFSC). Professora do Departamento de Expressão Gráfica da UFSC.

vanessa.arq@gmail.com

** Graduou-se em Arquitetura e Urbanismo pela Universidade de Brasília (UnB). Doutora pela Université de Paris I, Panthéon-Sorbonne, França. Professora do Curso de Pós-graduação em Arquitetura e Urbanismo da Universidade Federal de Santa Catarina (UFSC).

alina@arq.ufsc.br Referenciada desta forma por Francisco Homem de Melo $(1985,2005)$ e em estudos que abordam a relação
entre paisagem e informação provenientes de veículos de mídia exterior. 


\section{INTRODUÇÃO}

Este artigo tem como objetivo refletir sobre o papel do arquiteto na produção da paisagem informacional contemporânea, aquela dominada por signos e símbolos da comunicação visual urbana, muitas em situação de sobrecarga visual. É comum, em pesquisas que abordam esta temática, relacioná-la a profissionais de arquitetura e de comunicação social, em especial, aos publicitários, talvez porque a problemática da sobrecarga visual esteja relacionada com seu campo de atuação profissional.

No entanto, cabe salientar que grande parte dos pequenos estabelecimentos comerciais das cidades brasileiras não possui o auxílio de profissionais com estas formações. No caso das empresas de mídia exterior, largamente contratadas pelos estabelecimentos menores para confecção de placas de sinalização, muitas vezes não há a presença do profissional de comunicação, uma vez que a atividade pode ser executada por cidadãos com qualquer formação - prática recorrente nas cidades brasileiras, mais frequentes em cidades de porte maior, onde este tipo de comunicação está mais presente.

Uma vez que parece não haver interferência direta do arquiteto na produção destes espaços - que muitos denominam "caóticos" -, mas de milhares de cidadãos que transformam diariamente a estrutura e a paisagem das cidades, busca-se refletir sobre o real papel do arquiteto, em uma área que tudo indica ser de sua atribuição, e como ele está sendo preparado para a atuação profissional na mesma.

Otrabalho analisa, então, o grau em que a relação entre paisagem e comunicação visual urbana tem estado presente nas grades curriculares dos cursos de arquitetura e urbanismo das universidades brasileiras de maior visibilidade. ${ }^{2}$

Também é preciso entender como a paisagem das cidades, de um modo geral, é compreendida e abordada pelos profissionais de comunicação, em especial os publicitários, ciente de que sua interferência nestes cenários está bem aquém da interferência dos "publicitários da prática", aqueles que exercem a profissão sem o devido diploma.

Esta discussão teórica apóia-se em pesquisas de campo realizadas na área ao longo de cinco anos, que se complementam e corroboram os resultados alcançados.

Através desta reflexão, o trabalho busca apontar os possíveis caminhos para uma maior aproximação entre as duas áreas, que extrapolam seus campos de conhecimento específico e parecem necessitar da presença mais efetiva destes profissionais, publicitários e arquitetos, na sua produção - talvez, não através de projetos pontuais e individuais de cada estabelecimento, uma vez que sua contratação não é prática entre os proprietários. Talvez, então, a participação mais efetiva na produção destes espaços esteja na elaboração de diretrizes de controle e na produção de normas regulamentadoras, para além dos conhecidos projetos de reabilitação destes espaços.

Utilizou-se para esta pesquisa a classificação internacional estabelecida pela Webometric, que usa critérios de visibilidade para classificar as universidades. Disponível em: <http://www.webometrics.info/methodology. $\mathrm{html}$. . Acesso em: 15 fev 2012. 


\section{REFERENCIAL TEÓRICO}

A comunicação visual urbana (aqui entendida como comunicação ou mídia exterior) tem se imposto na paisagem das cidades desde o início do movimento moderno, a partir de 1930 (MENDES, 2006; MÜLLER-BROCKMANN, 1988) - e exercido, na contemporaneidade, um forte impacto na imagem dos cenários onde se apresenta (CARR, 1973; MINAMI, 2001; PORTELLA, 2007; VENTURI et al. 1998). Tem cada vez mais se afirmado como um dos elementos estruturadores da paisagem, algumas vezes no papel de "marcos-referências" (LYNCH, 1999; MELO, 1985), outras oferecendo identidade a bairros inteiros. Este tipo de comunicação é, segundo Cury (2004): " [...] porta-voz da informação, de valores e objetos culturais, sociais, econômicos, tecnológicos e consumistas da sociedade. Interage com os elementos da paisagem utilizando-os como suportes."

A utilização da fachada de edifícios como suporte (MINAMI, 2001) serve, mais frequentemente, para identificação das atividades comerciais que ocorrem no âmbito da edificação, e, também, para divulgação de marca, produto ou serviço fora do estabelecimento comercial, como o caso de outdoors e empenas cegas em edifícios.

\section{PROBLEMATIZANDO A RELAÇÃO ENTRE COMUNICAÇÃO VISUAL E PAISAGEM - A SITUAÇÃO DE SOBRECARGA VISUAL NA PAISAGEM URBANA}

[...] Nos sítios nos quais proliferam os objetos da comunicação visual urbana, as imagens invadem os espaços de circulação, de modo que todos os ângulos da visão são ocupados pelo excesso. A cor, as luzes, o movimento das chamadas para lojas e serviços são como uma pele para os prédios, que muda a cada nova loja que é inaugurada ou a cada nova campanha publicitária que ali se instala. Esses conjuntos visuais ocorrem em vias de alta densidade de fluxo e em áreas urbanas centrais ou polarizantes [...] $\bigcirc$ acúmulo resultante dessas manifestações expressivas pode causar o fenômeno da polvição visual. (ESPINOSA, 2004, p. 4).

Para Minami e Guimarães Júnior (2001, p. 2), a obstrução do campo visual do indivíduo, de maneira que dificulte sua percepção dos espaços da cidade, é o que se define como polvição visual. Entre as suas causas estão:

[...] o recobrimento da fachada dos edifícios por meio de anúncios publicitários e a colocação de anúncios cada vez maiores e em grande quantidade mascaram a identidade dos espaços da cidade, tornando-os inócuos e todos semelhantes, dificultando a orientação do cidadão e escondendo referenciais que fazem com que a cidade se diferencie de outras [...] Os anúncios passam a encobrir, ocupar o lugar ou substituir os marcos referenciais dos lugares [...]. 
Mendes e Vargas (2002), em seus estudos sobre a paisagem de São Paulo anteriores à recente regulamentação ${ }^{3}$, fazem referência à permissividade da antiga Lei Municipal de São Paulo n 13.525, de 28 de fevereiro de 2003, que regulamentava os anúncios publicitários visíveis do espaço público. De acordo com Passini (1984), concentrações urbanas de comércio e entretenimento, geralmente, destacam-se pela alta quantidade de estímulos de todos os tipos - dentre eles, os visuais.

A capacidade de processar informações tem um limite natural, que varia de acordo com o indivíduo e com os canais de percepção envolvidos. Condições de estímulo que excedem a capacidade de processamento são denominadas, segundo Passini (1984), sobrecarga de estímulo. Para o autor, quanto maior a quantidade de informações no cenário, maior a dificuldade de encontrar uma informação em particular, simplesmente porque a pessoa tem que selecionar, identificar e reter tal informação dentre várias outras.

Esta dificuldade não é a única. Ambientes densos em informação - por requererem maior dedicação e atenção do usuário - podem tornar-se cansativos, e a fadiga diminui o percentual de eficiência. Em algumas situações, pode haver aumento da ansiedade devido à quantidade de informações excessiva, que, por sua vez, também inibe o processamento das mesmas. Portella (2007), na tentativa de melhorar a qualidade visual dos centros históricos que enfrentam a problemática da polvição visual, identificou uma série de aspectos que devem ser levados em consideração ao estabelecer-se formas de controle das práticas de publicidade na paisagem destes locais. Um destes aspectos é a importância da implementação de um mecanismo nacional de controle dos anúncios na paisagem em países como o Brasil, onde a administração pública muda com frequência e os projetos e as regulamentações de administrações anteriores são modificados ou deixados de lado.

Na tentativa de melhorar a qualidade visual do espaço urbano, há uma recente regulamentação ocorrida na cidade de São Paulo através da Lei n ${ }^{\circ} 14.223$, de 26 de setembro de 2006, a polêmica "lei Cidade Limpa".

Outras cidades também têm mostrado preocupação com a questão e possuem esta regulamentação no âmbito de suas leis municipais (Planos Diretores, Códigos de Posturas e leis específicas). Porém, não há consenso quanto aos parâmetros de regulamentação, e, além de poucas cidades terem a lei aplicada na prática, a permissividade de algumas permite que se construam cenários com esta problemática, como o caso da cidade de Santa Maria, no Rio Grande do Sul (CASARIN, 2004; 2007). Cullen (2002, p. 153156), em seu livro Paisagem urbana, já fazia as seguintes considerações a respeito do conflito entre publicidade e paisagem: "[...] os anúncios e publicidade nas ruas, embora quase totalmente ignorados pelos urbanistas constituem uma contribuição para a paisagem urbana. $\bigcirc$ autor diz que: "[...] torna-se quase desnecessário referir que toda esta publicidade deve ser cuidadosamente controlada, e que certos tipos de obscenidades devem ser evitados a todo custo. (CULLEN, 2002, p. 153-156). 
Para Cullen (2002), os quatro argumentos utilizados para contrariar a publicidade de rua, são os seguintes:

a) os anúncios são incongruentes e contrários ao bem-estar dos indivíduos;

b) invadem espaços públicos de modo que os indivíduos são obrigados a repará-los;

c) banalizam o ambiente urbano e degradam o gosto popular;

d) distraem motoristas e transeuntes.

No entanto, de acordo com o autor, somente este último argumento parece ser realmente prejudicial e digno de ser levado em consideração, visto que pode ser causa de acidente grave.

No início do período moderno, quando a problemática do excesso de anúncios começou a tomar corpo, parece ter ficado mais visível a distinção entre comércio de alto padrão e comércio popular, no que se refere à comunicação visual. Segundo Mendes (2006), ao passo que o comércio de alto padrão se utilizava de comunicação visual discreta, o comércio popular refletia o excesso, o que se percebia no âmbito da edificação e se refletia na paisagem da cidade, como mostra a figura 1.

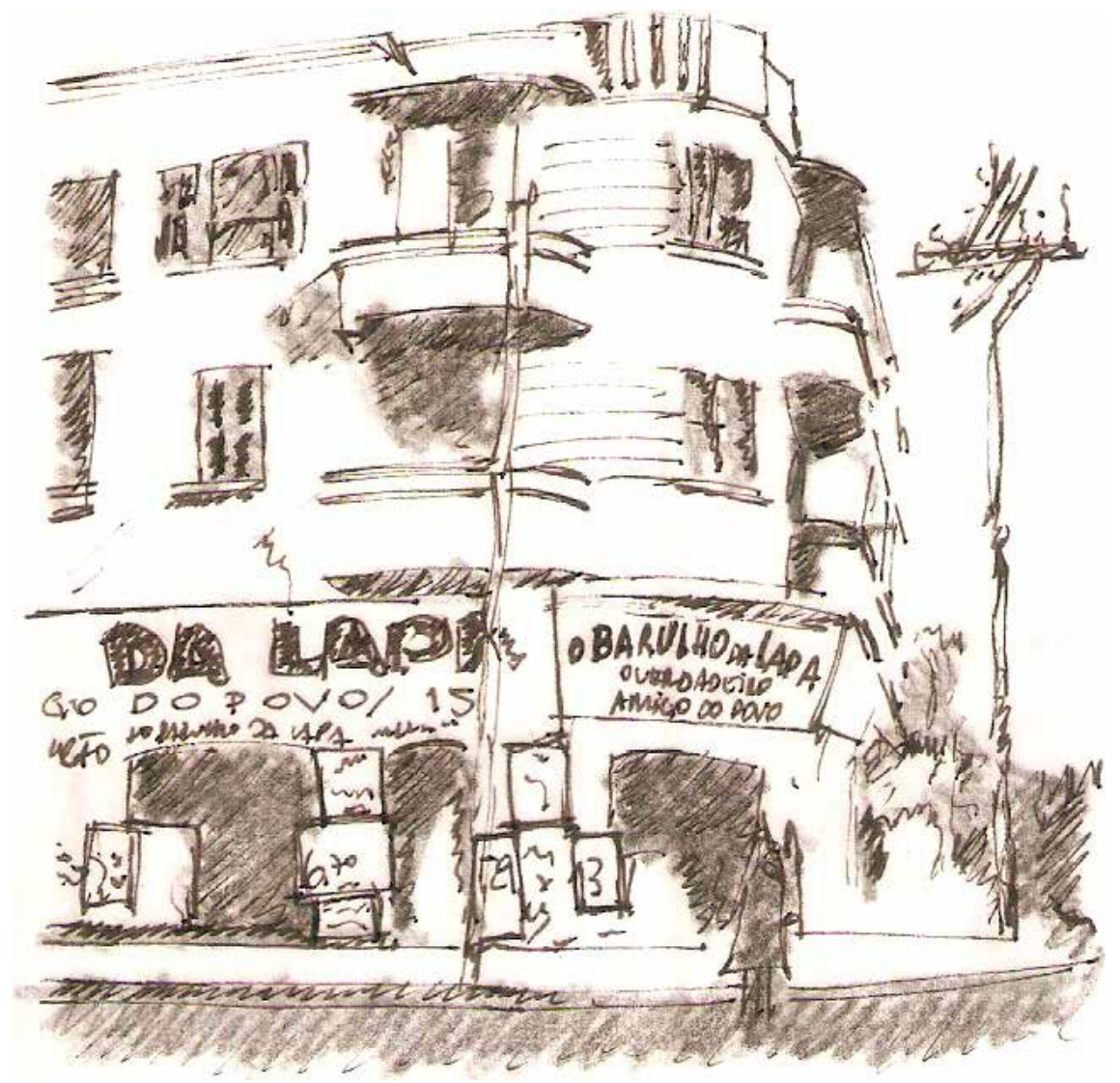

Figura 1 Fachada da loja O Barulho da Lapa em 1950.

Ilustração de Vanessa Casarin, 2012, a partir de fotografia de Alice Brill.

Fonte: Mendes (2006). 
Para compreender melhor a relação do profissional de arquitetura com a publicidade ao ar livre, e o oposto, a relação do profissional de comunicação com a paisagem e o edifício e o papel destes profissionais nas causas do problema apresentado é necessário, antes, compreender o processo de projeto.

\subsection{A MÍDIA EXTERNA NA CONCEPÇÃO PROJETUAL DO ARQUITETO}

A preocupação do arquiteto com a informação na concepção projetual é facilmente verificada em inúmeros projetos - e de longa data, conforme se observa nos escritos de Cullen sobre a publicidade na paisagem, que datam de 1961.

O bom domínio dos princípios do desenho e da percepção visual ${ }^{4}$ por parte do arquiteto e a consideração da informação como um condicionante de projeto (fazendo parte do programa estabelecido) faz com que arquitetura e anúncio constituam uma unidade.

A informação é uma das partes do todo arquitetônico, que, em uma obra de arquitetura, busca a convivência harmônica, a constituição de uma unidade formal (MAHFUZ, 1995) - como pode ser verificado no projeto da loja Forma (figura 02), obra do arquiteto Paulo Mendes da Rocha, e da loja Havaianas (figura 03), obra do também arquiteto Isay Weinfeld. Nelas, o contraste e a relação figura-fundo são cuidadosamente respeitados na área da fachada.

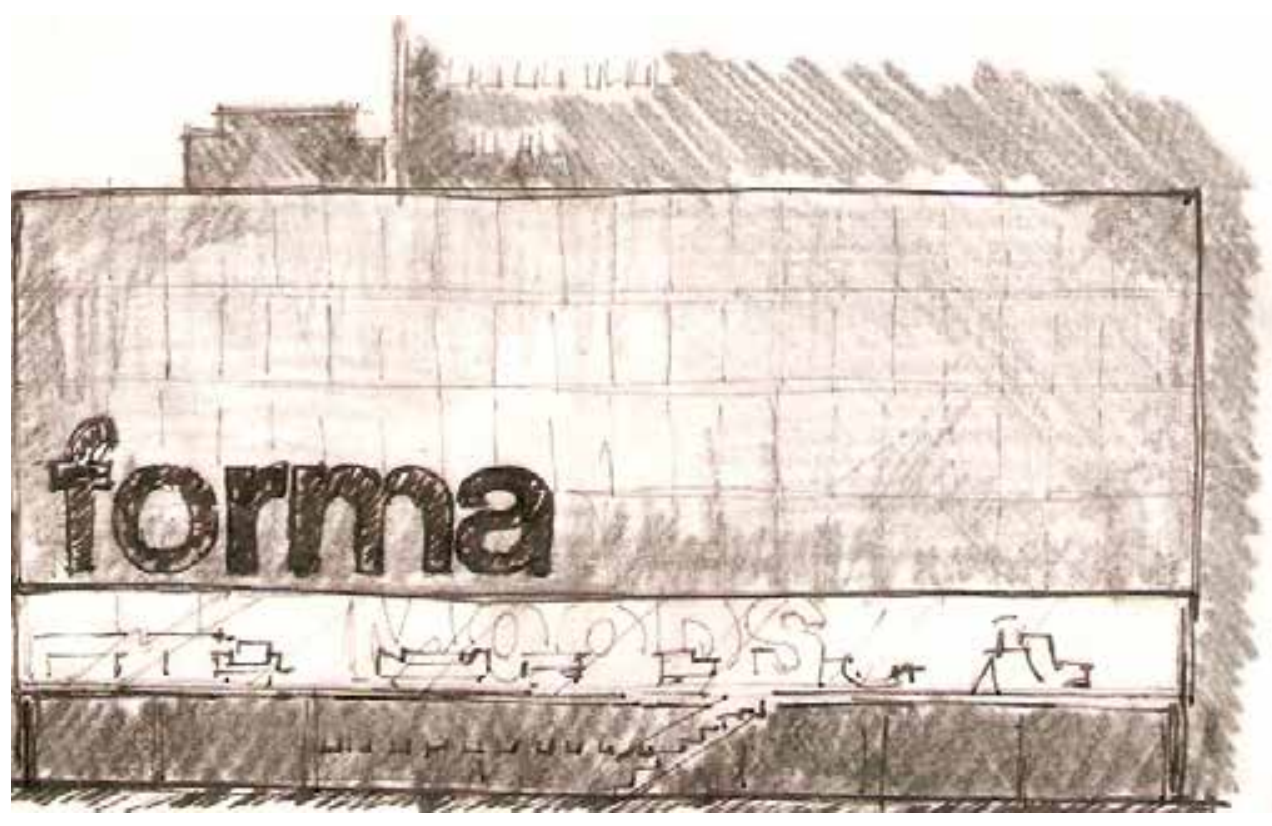

Figura 2 Loja Forma. São Paulo (SP). Arquiteto Paulo Mendes da Rocha. llustração: Vanessa Casarin, 2012.

\footnotetext{
$4 \quad$ Alguns dos princípios da percepção visual são identificados por Arnheim (1997) como: equilíbrio, configuração, forma, desenvolvimento, espaço (onde está inserida a relação figura e fundo, tão importante na relação entre publicidade e paisagem), luz, cor, movimento, dinâmica e expressão.
} 


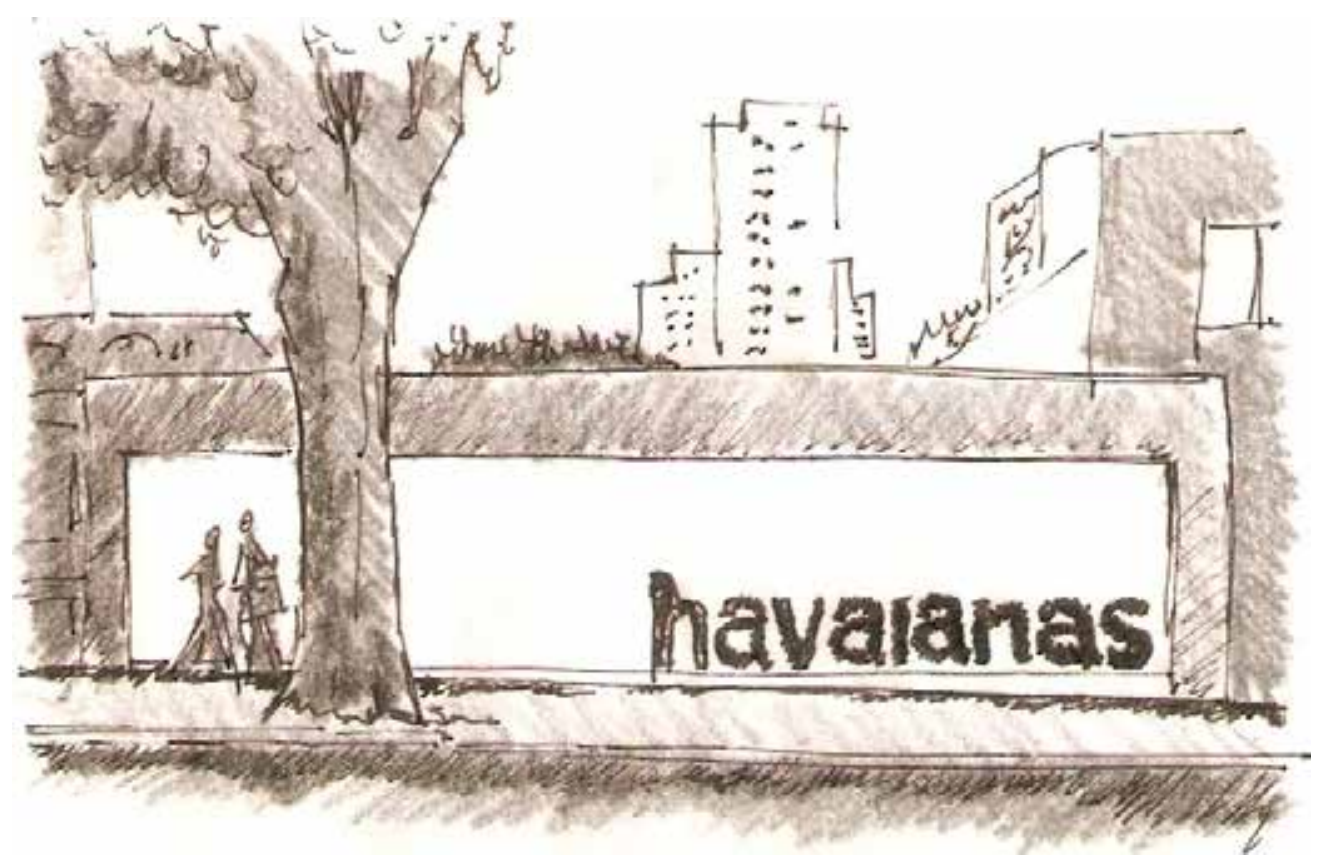

Figura 3 Loja Havaianas. São Paulo (SP). Arquiteto Isay Weinfeld. Ilustração: Vanessa Casarin, 2012.

Também é crescente nos cursos de arquitetura e urbanismo a inserção de disciplinas que abordam a comunicação visual, sobretudo, a urbana.

Quando a informação não tem a oportunidade de ser concebida junto com o edifício, para que exista harmonia entre arquitetura e anúncio, o edifício como um todo precisa ser considerado pelo profissional de comunicação. Quando aumentamos a escala de percepção, necessita o profissional de comunicação compreender a paisagem onde o anúncio será inserido como um todo.

\subsection{A PAISAGEM E O EDIFÍCIO NA CONCEPÇÃO DO ANÚNCIO}

Uma pesquisa realizada por Casarin (2004) na cidade de Santa Maria (RS), com os publicitários responsáveis pelas agências de comunicação certificadas pelo Conselho Executivo das Normas-Padrão (CENP) ${ }^{5}$, revelou que todos os entrevistados consideravam que a comunicação visual deveria se adequar à paisagem respeitando o patrimônio histórico (arquitetura dos edifícios) e cultural das cidades. Porém, ao serem perguntados se levavam em consideração a paisagem urbana ao elaborar peças de comunicação, a maioria respondeu não o fazer 6 .

5 O Conselho Executivo das Normas-Padrão (CENP) é uma entidade criada pelo mercado publicitário para zelar pela observância das Normas-Padrão da Atividade Publicitária, documento básico que define as condutas e regras das melhores práticas éticas e comerciais entre os principais agentes da publicidade brasileira, que existe desde 1998.

6 Transcrição das falas dos entrevistados que corroboram a afirmativa: "Para alguns poucos clientes, sim; aqueles que já têm esta consciência; para a grande maioria não se consegue chegar a este ponto de sofisticação." (entrevistado 2). "Via de regra, criamos as peças de mídia exterior e já existem pontos definidos, determinados pela exibidora. Dentro destes pontos, tentamos sempre ver quais os de maior frequência de pessoas, carros, para optar por aqueles pontos." (entrevistado 4). "Raramente. Infelizmente, nem sempre fazemos tudo do jeito como queremos, pois nunca criamos para nós mesmos, sempre para os clientes." (entrevistado 06). "Sinceramente, 
Os publicitários, ao levarem em conta a paisagem na elaboração do anúncio, visam buscar a melhor localização das mídias para que atinjam o maior público (maior quantidade de pessoas passando no local) ou o seu público-alvo. Ao mesmo tempo, analisam a paisagem apenas como o fundo da peça publicitária, como pode ser observado na reprodução da fala do entrevistado: "[...] quando produzo uma peça publicitária de outdoor, procuro avaliar, em primeiro lugar, qual o ponto onde ele vai estar. Se vai estar dentro de uma área superpoluída por edifícios e casinhas, não adianta fazer uma programação visual numa folha em branco, porque não é nesse ambiente que a peça vai estar. $\bigcirc$ que nós fazemos é definir os pontos: visitamos, fotografamos, e, então, criamos a peça. Tento criar uma moldura que possa já estar dentro do outdoor e daí coloco a imagem colorida, porque a moldura branca que criei vai salientar a peça." (entrevistado 1).

A incipiente consideração da paisagem na elaboração das peças publicitárias talvez possa ser explicada por uma deficiente abordagem do tema nos cursos de comunicação social. Também é valido mencionar que o curso de comunicação social com habilitação em publicidade e propaganda procura habilitar o profissional a despertar o desejo do cliente e convencê-lo a comprar acima de tudo. Os fins lucrativos são bastante explícitos quando se trabalha com publicidade e propaganda - em detrimento de muitos outros, como o da qualidade da paisagem de um modo geral.

Ainda em relação à pesquisa supracitada, cabe destacar que a maioria dos entrevistados concorda que os centros urbanos estão poluídos visualmente e que as fachadas das edificações têm pouca interferência na intenção de compra do consumidor - a boa apresentação da fachada é vista pelos publicitários como uma obrigação do lojista para com o cliente. Mencionam, ainda, que a influência da compra se dá por um processo muito maior, que envolve diversos tipos de mídia - opinião compartilhada por Espinosa (2004) e Cury (2004) em suas publicações sobre o tema.

É importante salientar que a mídia exterior ${ }^{7}$ é considerada eficiente pela totalidade dos entrevistados, e a maioria deles também considera que a sua inserção na paisagem deveria ser de alguma forma controlada.

$\bigcirc$ resultado desta pesquisa corrobora os resultados alcançados pela pesquisa exploratória apresentada por Mendes e Vargas (2002), realizada na cidade de São Paulo. As autoras concluíram que:

[...] há pouca interferência desta caótica publicidade nas intenções de compra dos usuários, ou então, que tais interferências estão mais ligadas aos processos inconscientes de percepção ambiental, que não é facilmente identificável pelos entrevistados. (MENDES; VARGAS, 2002, p. 1).

não, pois o que consideramos realmente na hora de anunciar é a quantidade de pessoas que vamos atingir anunciando em determinado veículo. No caso do outdoor, definimos os pontos bem localizados na cidade, onde um número maior de pessoas circula diariamente." (entrevistado 7).

7 Porém, cabe salientar que os pontos são preestabelecidos pelas Companhias e que, quando se referem a esta mídia, não estão se referindo apenas ao anúncio da fachada (que, como já mencionado, tem pouca interferência na intenção de compra do consumidor), mas à mídia externa como um todo, o que envolve outdoors, infláveis, e outros veículos de mídia externa. 


\section{METODOLOGIA}

A pesquisa exploratória busca cruzar os resultados do referencial teórico estudado e de pesquisas ${ }^{8}$ anteriores na área com uma busca dentre as grades curriculares dos cursos de arquitetura das universidades brasileiras mais bem colocadas entre as dez primeiras classificadas no ranking sul-americano da Webometrics - classificadas de acordo com critérios de visibilidade, de disciplinas relacionadas à comunicação visual urbana - com o objetivo de se compreender em que grau os conceitos abordados se encontram na formação do arquiteto.

Dentre as universidades analisadas estão a Universidade de São Paulo (USP), a Universidade Estadual de São Paulo (UNESP), a Universidade Federal do Rio Grande do Sul (UFRGS), a Universidade Federal de Santa Catarina (UFSC), a Universidade Estadual de Campinas (Unicamp), a Universidade Federal de Brasília (UnB) e a Universidade Federal do Paraná (UFPR).

A seleção da Webometrics ${ }^{9}$ como parâmetro de classificação se dá no momento em que se considera a acessibilidade à informação produzida por instituição de ensino de relevada importância para pesquisas em qualquer âmbito e para a informação da comunidade de um modo geral. Os critérios e visibilidade propostos pela Webometrics foram julgados adequados pelo pesquisador para sua seleção como parte integrante da metodologia, uma vez que visibilidade e acesso caminham juntos na democratização do conhecimento e o resultado apresentado pela instituição de pesquisa corrobora com a experiência empírica em termos de reconhecimento acadêmico das instituições supracitadas $^{10}$.

\section{DISCUSSÃO E RESULTADOS}

A problemática apresentada no referencial teórico deste trabalho é confirmada pelas duas pesquisas apresentadas. Percebe-se que o excesso, a falta de qualidade e a desordenação dos anúncios em relação às edificações ou à arquitetura, de modo geral são percebidos de forma negativa pelos usuários dos locais onde há uma alta concentração dos mesmos.

Tanto na visão dos responsáveis pelas agências de comunicação quanto na percepção dos usuários da rua de comércio pesquisada, o excesso de anúncios que está

3 Pesquisa realizada em 2004 (CASARIN, 2004), de caráter qualitativo, foi realizada com os profissionais responsáveis pelas agências de Publicidade e Propaganda regulamentadas pelo CENP na cidade de Santa Maria (RS). O método adotado fez uso de entrevistas face a face, gravadas e posteriormente transcritas. Os resultados foram tratados através da análise de conteúdo, com o estabelecimento de categorias de análise geradas após a aplicação da pesquisa.

9 Pesquisa realizada em 2007 (CASARIN, 2007), envolveu um estudo de caso realizado com base na percepção dos usuários da paisagem de uma dada área de estudo, no mesmo município, onde a relação arquitetura-anúncio acontecia de maneira expressiva. Foi escolhido o trecho da principal rua de comércio da cidade, que apresentava o maior percentual de cobertura das fachadas por anúncios publicitários. A amostra, estratificada segundo o uso do espaço, envolveu usuários eventuais e trabalhadores do local, num total de trinta e três respondentes. O estudo envolveu entrevistas qualitativas gravadas e transcritas, tratadas através da análise de conteúdo.

10 Maiores informações a respeito da metodologia utilizada estão descritas no site da instituição de pesquisa. Disponível em: <http://www.webometrics.info/methodology.html>. Acesso em: 15 fev 2012. 
presente na paisagem deve ser de alguma forma controlado. A situação não prejudica apenas os usuários das cidades, mas estabelece dificuldades ainda para os que criam as peças publicitárias e têm como objetivo destacá-las na paisagem. Esta não é levada em consideração pelos anunciantes ao elaborar uma peça de comunicação e deixá-la visível no espaço público, salvo nos casos em que precisa ser considerada para que a peça tenha visibilidade.

Dentro do processo de projeto do arquiteto, considerando que a ideia vem de conhecimentos prévios da problematização estabelecida, dos referenciais projetuais, da subjetividade de um modo geral (SILVA, 1986), não é difícil perceber por que a informação está presente na concepção projetual deste profissional desde o início da tarefa, pois, além de fazer parte do programa de necessidades estabelecido, tem ocorrido a inserção, na grade curricular dos cursos de arquitetura e urbanismo, de disciplinas (obrigatórias ou optativas) sobre outros campos do saber, que complementam a formação do arquiteto, sendo ofertadas de acordo com a necessidade da demanda estabelecida. Disciplinas como sociologia há bastante tempo fazem parte da grade dos cursos de arquitetura e urbanismo. Mais recentemente, percebe-se a oferta de disciplinas que se aproximam da área da comunicação visual, como a semiótica, a programação visual e até mesmo disciplinas intituladas "comunicação visual".

A análise das grades curriculares dos cursos de arquitetura e urbanismo mencionados na metodologia deste trabalho, e suas respectivas ementas, revelaram que a USP é, sem dúvida, a instituição mais preocupada em inserir a questão na formação do arquiteto, oferecendo amplo suporte à sua atividade profissional na área, possuindo um núcleo inteiro de disciplinas de programação visual, no qual duas disciplinas são obrigatórias e as demais eletivas.

A UFSC também aborda o assunto nas disciplinas obrigatórias, porém, associado a uma disciplina de projeto arquitetônico (intitulada "projeto arquitetônico") e programação visual. Oferece, também, uma disciplina optativa específica de programação visual.

UFRGS, Unicamp, UFRJ e UnB oferecem disciplinas em torno do assunto apenas como eletivas, no entanto, a UFRGS mostra preocupação específica com a questão da polvição visual urbana na própria ementa da disciplina. UNESP e UFPR não abordam o conteúdo em disciplina específica, no entanto, não se pode afirmar que o conteúdo não seja tratado na grade curricular destes cursos dentro de qualquer outra disciplina obrigatória.

Resta saber como ocorre a inserção dos estudos da cidade, da paisagem e do edifício, que servem de suporte à mídia externa nos cursos de comunicação social.

Os resultados apontaram que há pouca interferência do arquiteto na produção das paisagens com sobrecarga visual. Seu papel está na conscientização acerca desta problemática e a possibilidade de maior interferência neste processo de produção está no ensino e na participação mais efetiva em processos de controle de tais manifestações na paisagem urbana, uma vez que planejá-las é sua atribuição profissional.

A grade curricular da maioria das universidades pesquisadas tem refletido a preocupação com este assunto, no sentido de preparar o arquiteto para a atuação nesta 
área. Dentre as universidades pesquisadas, o melhor exemplo em relação a esta problemática está na USP.

Como resultado desta reflexão, e através do apontamento das pesquisas de campo, percebe-se que o signo informacional está mais presente na concepção arquitetônica do que a arquitetura é considerada na elaboração de peças e campanhas de publicidade.

Se a maioria dos publicitários considera que a fachada tem pouca influência na intenção de compra, o que corrobora as pesquisas de Mendes e Vargas (2002), e que é obrigação do proprietário do estabelecimento manter a boa apresentação deste, e que a publicidade deve ser, de alguma forma, controlada na paisagem, pode-se dizer que a interferência deste profissional na problemática encontrada nas cidades é pequena, e que a conscientização acerca do problema existe, o que é um grande passo para a colaboração interdisciplinar na busca pela solução.

No entanto, deve-se perceber que o excesso de anúncios nas paisagens das cidades extrapola os dois campos do conhecimento, arquitetura e urbanismo e comunicação social, visto que a cidade, cujas paisagens acolhem edifícios e anúncios publicitários, é fruto, como bem coloca Lynch (1999), de milhões de construtores que nunca deixam de transformar sua estrutura. Em grande parte dos estabelecimentos comercias de uma cidade, não existe a participação de um profissional de arquitetura ou publicidade que orientem sua apresentação ao público. A produção dos espaços atingidos por esta problemática parece não ter, portanto, grande interferência de publicitários e, em menor grau, de arquitetos.

Quanto aos arquitetos, uma participação mais efetiva estaria vinculada à elaboração de programas e políticas de controle da comunicação visual urbana e a projetos de requalificação dos espaços urbanos degradados por essa prática.

Assim, apontam-se caminhos para a solução do problema que vão além da concepção projetual, seja do edifício ou do anúncio, e fica clara a importância dos diferentes atores e da contribuição que cada um pode dar na busca por uma solução interdisciplinar.

problema está na conscientização dos próprios lojistas, como apontado por Mendes e Vargas (2002):

[...] Uma legislação orientadora, uma fiscalização eficiente e, principalmente uma conscientização dos varejistas de que este tipo de propaganda e de espaço varejista não contribui para a melhoria da rentabilidade do seu negócio, pode ser um primeiro passo para a mudança da situação hoje existente nos espaços varejistas. (Disponível em: <http://www.vitruvius.com.br/arquitextos/arq000/esp116.asp>. Acesso em: 16 nov. 2004).

Esta foi a forma encontrada pela Prefeitura de São Paulo para a solução do problema, ordenando a retirada dos anúncios, e, se bem observada a Lei n. ${ }^{\circ} 14.223 / 20$, de 26 de setembro de 2006, fica claro que a intenção não é a proibição, mas a ordenação, pois a Lei sugere uma série de diretrizes para que se desenrole de forma mais adequada para cada cenário da paisagem. Como coloca Lynch (1999, p. 101): 
Temos a oportunidade de transformar o nosso novo mundo urbano numa paisagem passível de imaginabilidade: visível, coerente, clara. Isso vai exigir uma nova atitude de parte do morador das cidades e uma reformulação do meio em que ele vive. As novas formas, por sua vez, deverão ser agradáveis ao olhar, organizar-se nos diferentes níveis no tempo e no espaço e funcionar como símbolos da vida urbana.

\section{CONSIDERAÇÕES FINAIS}

Percebe-se que o signo informacional está mais presente na concepção arquitetônica do que a arquitetura é considerada na elaboração de peças e campanhas de publicidade. $\bigcirc$ mesmo parece acontecer em relação às grades curriculares dos cursos de formação destes profissionais, arquitetos e publicitários. No entanto, quanto à formação dos profissionais de comunicação, ainda é um caso a se pesquisar.

Conclui-se que, para a qualificação dos espaços de nossas cidades, principalmente nos centros de comércio, é necessário melhorar a relação entre a comunicação visual e a paisagem, entre a arquitetura e o anúncio, que deve constituir uma via de mão dupla, com esforços de ambos os lados e de todos os profissionais envolvidos, os da prática e os de direito.

No entanto, o excesso de anúncios nas paisagens das cidades extrapola os dois campos do conhecimento - arquitetura e urbanismo e comunicação social e, sobretudo, o visual, visto que as paisagens das cidades são frutos de milhões de construtores, cidadãos comuns que nunca deixam de transformá-las.

Os caminhos parecem apontar para formas de controle que levem em consideração um trabalho de conscientização dos que, efetivamente, produzem os cenários comerciais das cidades, em especial os de comércio popular - que raramente possuem apoio técnico especializado - e também dos cidadãos que se utilizam destes espaços no dia a dia. Um espaço urbano com boa qualidade visual oferece melhor qualidade de vida para quem dele usufrui.

Um trabalho neste sentido foi iniciado em São Paulo através da Lei n. ${ }^{\circ}$ 14.223/2006, conhecida como Lei da Cidade Limpa, cujas diretrizes parecem apontar para uma solução.

Cabe salientar que, muitas vezes, a conscientização dos que ocupam as cidades de modo predatório só se dá pela imposição. A implantação da referida lei em São Paulo pode ter parecido arbitrária em um primeiro momento, no entanto, ofereceu ao cidadão paulistano uma nova forma de ver sua cidade, o que pode representar um primeiro passo no processo de conscientização acerca do assunto. 


\section{REFERÊNCIAS BIBLIOGRÁFICAS}

ARNHEIM, Rudolf. Arte e percepção visual: uma psicologia da visão criadora. São Paulo: Pioneira, 1997.

CARR, Stephen. City, signs and lights. Cambridge: MIT, 1973.

CASARIN, Vanessa. Excedendo os limites: publicidade externa e polvição visual. 2004. 111 f. Trabalho de Conclusão de Curso. Comunicação Social. CCSH/DCC - Universidade Federal de Santa Maria, Santa Maria, 2004.

2007. 168 f. A mídia externa e o ambiente construído na paisagem urbana: um estudo de caso. Dissertação (Mestrado em Arquitetura e Urbanismo - PósARQ). Universidade Federal de Santa Catarina, Florianópolis, 2007.

CULLEN, Gordon. Paisagem urbana. Lisboa: Edições 70, 2002.

CURY, Luis Fernando. As paisagens da comunicação ao ar livre. In: Congresso Brasileiro de Ciências da Comunicação - INTERCOM, 27, 2004, Porto Alegre. Anais... Porto Alegre. CD-ROM.

ESPINOSA, Lara. Polvição visual: um problema de comunicação. In: Congresso Brasileiro de Ciências da Comunicação, INTERCOM, 27, 2004. Porto Alegre. Anais... Porto Alegre. CD-ROM.

LYNCH, Kevin. A imagem da cidade. São Paulo: Martins Fontes, 1999.

MAHFUZ, Edson da Cunha. Ensaio sobre a razão compositiva: uma investigação sobre a natureza das relações entre as partes e o todo na composição arquitetônica. Belo Horizonte: UFV Imprensa Universitária/AP Cultural. 1995.

MELO, Francisco Inácio Scaramelli Homem de. 1985. Caos e ordem no ambiente urbano: exploração visual do signo arquitetônico e do signo informacional. Dissertação (Mestrado em Arquitetura e Urbanismo) - Faculdade de Arquitetura e Urbanismo da Universidade de São Paulo, São Paulo, 1985.

Signofobia. São Paulo: Rosari, 2005.

MENDES, Camila Faccioni. Paisagem urbana: uma mídia redescoberta. São Paulo: Senac, 2006.

; VARGAS, Heliana Comin. Poluição visual e paisagem urbana: quem lucra com o caos? Disponível em: $\overline{<h t t p: / / w w w . v i t r u v i u s . c o m . b r / a r q u i t e x t o s / a r q 000 / e s p 1 ~ 16 . a s p>. ~ A c e s s o ~ e m: ~} 16$ nov. 2004.

MINAMI, Issao. Paisagem urbana de São Paulo: publicidade externa e polvição visual. Disponível em: <http:// www.vitruvius.com.br/arquitextos/arq000/esp074.asp>. Acesso em: 16 nov. 2004.

; GUIMARÃES JÚNIOR, João Lopes. A questão da ética e da estética no meio ambiente urbano ou porque todos devemos ser belezuras. 2001. Disponível em: <http://www.vitruvius.com.br/arquitextos/arq000/ esp094.asp>. Acesso em: 16 nov. 2004.

MÜLLER-BROCKMANN, Josef. Historia de la comunicación visual. Barcelona: G. Gili, 1988.

PASSINI, Romedi. Wayfinding in architecture. New York, USA, Van Nostrand Reinhold Company Inc. 1984.

PORTELLA, Adriana Araújo. 2007. 604 f. Evaluating commercial signs in historic streetscapes: the effects of the control of advertising and signage on user's sense of environmental quality. Tese (Doutorado em Desenho Urbano) Oxford Brookes University, Oxford, England, 2007.

SILVA, Elvan. Sobre a renovação do conceito de projeto arquitetônico e sua didática. In: COMAS, Carlos Eduardo (Org.). Projeto arquitetônico: disciplina em crise, disciplina em renovação. São Paulo: Projeto Editores Associados, 1986.

VENTURI, Robert; IZENOUR, Steve; BROWN, Denise Scott. Apriendendo de Las Vegas. Barcelona: Gustavo Gilli, 1998.

Artigo recebido em 16 mai. 2012 
